\title{
Increased osteoblast adhesion on nanograined hydroxyapatite and tricalcium phosphate containing calcium titanate
}

\author{
Celaletdin Ergun, ${ }^{1}$ Huinan Liu, ${ }^{2}$ John W. Halloran, ${ }^{3}$ Thomas J. Webster ${ }^{2}$ \\ ${ }^{1}$ Mechanical Engineering Department, Istanbul Technical University, Taksim, 34437 Istanbul, Turkey \\ ${ }^{2}$ Division of Engineering, Brown University, Providence, Rhode Island 02912 \\ ${ }^{3}$ Materials Science and Engineering, The University of Michigan, Ann Arbor, Michigan 48109
}

Received 19 March 2006; revised 1 May 2006; accepted 15 May 2006

Published online 21 November 2006 in Wiley InterScience (www.interscience.wiley.com). DOI: 10.1002/jbm.a.30923

\begin{abstract}
Depending on the coating method utilized and subsequent heat treatments (such as through the use of plasma-spray deposition), inter-diffusion of atomic species across titanium (Ti) and hydroxyapatite (HA) coatings may result. These events may lead to structural and compositional changes that consequently cause unanticipated HA phase transformations which may clearly influence the performance of an orthopedic implant. Thus, the objective of the present in vitro study was to compare the cytocompatibility properties of chemistries that may form at the Ti:HA interface, specifically HA, tricalcium phosphate (TCP), HA doped with $\mathrm{Ti}$, and those containing calcium titanate $\left(\mathrm{CaTiO}_{3}\right)$. In doing so, results of this study showed that osteoblast (bone-forming cells) adhesion increased with greater $\mathrm{CaTiO}_{3}$ substitutions in either HA or TCP. Specifi-
\end{abstract}

cally, osteoblast adhesion on HA and TCP composites with $\mathrm{CaTiO}_{3}$ was almost 4.5 times higher than that over pure HA. Material characterization studies revealed that enhanced osteoblast adhesion on these compacts may be due to increasing shrinkage in the unit lattice parameters and decreasing grain size. Although all $\mathrm{CaTiO}_{3}$ composites exhibited excellent osteoblast adhesion results, $\mathrm{Ca}_{9} \mathrm{HPO}_{4}\left(\mathrm{PO}_{4}\right)_{5}$ $\mathrm{OH}$ phase transformation into $\mathrm{TCP} / \mathrm{CaTiO}_{3}$ increased osteoblast adhesion the most; because of these reasons, these materials should be further studied for orthopedic applications. (C) 2006 Wiley Periodicals, Inc. J Biomed Mater Res 80A: 990-997, 2007

Key words: calcium phosphate; titanate; hydroxyapatite; osteoblasts; adhesion; orthopedic

\section{INTRODUCTION}

Mechanical properties are the principal limitation in the clinical use of hydroxyapatite (HA) as a bulk material in orthopedic load-bearing applications. Therefore, HA is commonly utilized as a coating material on traditional metallic substrates in order to take advantage of their exceptional cytocompatibility properties coupled with the necessary mechanical properties of the underlying metal. ${ }^{1}$

Depending on the coating method utilized and subsequent heat treatments (such as through the use of plasma-spray deposition), interdiffusion of atomic species across the metal and HA coating may result. However, these events may lead to structural and compositional changes that consequently cause unan-

Correspondence to: T.J. Webster; e-mail: Thomas_Webster@ Brown.edu

Contract grant sponsor: Scientific \& Technological Research Council of Turkey

(C) 2006 Wiley Periodicals, Inc. ticipated HA phase transformations. Clearly, this new material formed at the metal/HA interface will have numerous consequences in terms of cytocompatibility. For example, this unwanted material may cause toxic reactions in the body, decrease osteoblast (or bone-forming cells) adhesion, and/or alter the interfacial bond strength with the underlying metal. ${ }^{2}$

Previous research on titanium (Ti) and HA coatings revealed significant elemental Ti diffusion into the HA structure $^{3,4}$; specifically, calcium titanate $\left(\mathrm{CaTiO}_{3}\right)$ may be formed as a result of this atomic diffusion at the Ti:HA coating interface. ${ }^{2,5}$ Importantly, it has been demonstrated that $\mathrm{CaTiO}_{3}$ increases osteoblast adhesion compared to both pure HA and $\mathrm{Ti}$ and, thus, could possibly be beneficial if formed during the coating process. The presence of $\mathrm{CaTiO}_{3}$ (which is stable in an acidic environment) further decreases the dissolution of HA in low $\mathrm{pH}$ conditions that may be created by osteoclast bone resorption or due to an inflammatory response. ${ }^{6}$ In this manner, $\mathrm{CaTiO}_{3}$ could increase the stability of bioactive HA on Ti. Further, significant apatite growth on $\mathrm{CaTiO}_{3}$ in simulated body fluid (SBF) has been observed, thus, providing promise for 
TABLE I

Abbreviation and the Composition of the Compacts Tested in the Present Study

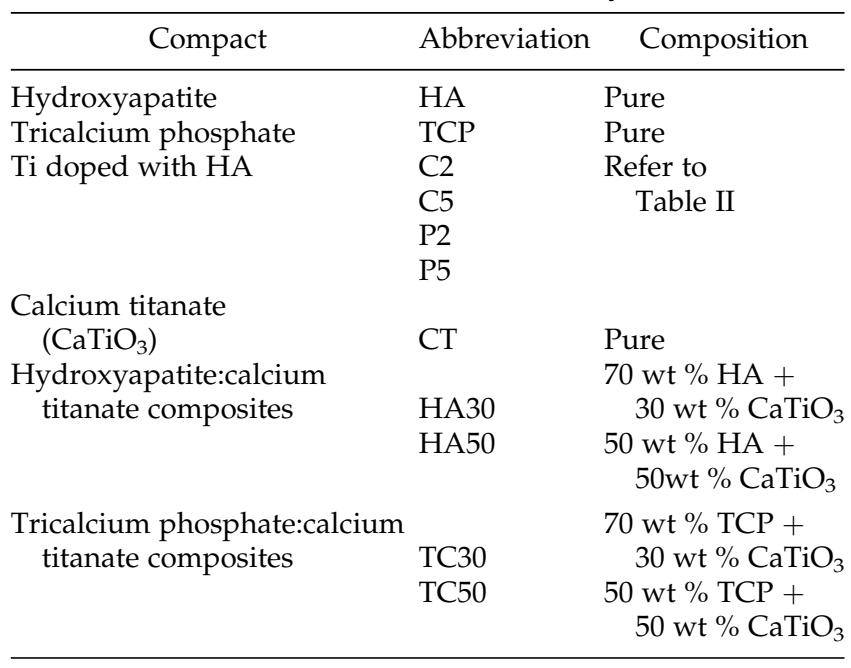

the formation of bone-like structures on $\mathrm{CaTiO}_{3}{ }^{7}$ Therefore, $\mathrm{CaTiO}_{3}$ itself may be regarded as a desirable interfacial bioceramic for orthopedic implant applications. $^{8}$

To improve mechanical and biological properties of orthopedic implants, it is thus possible to design single-phase materials or composite-based materials with $\mathrm{CaTiO}_{3}$; however, this remains largely uninvestigated. For this reason, the objective of the present in vitro study was to compare the cytocompatibility properties of chemistries that may form at the Ti:HA interface, specifically HA, tricalcium phosphate (TCP), HA doped with $\mathrm{Ti}$, and those containing $\mathrm{CaTiO}_{3}$. Specifically, pure HA, pure TCP, and Ti doped with HA were synthesized using well-established wet chemistry precipitation methods. The composites of HA and TCP with $\mathrm{CaTiO}_{3}$ were prepared using powder mixing. The re-
TABLE II

Percent Weight Composition of Ti Doped with HA

\begin{tabular}{ccccc}
\hline $\begin{array}{c}\text { Ti Doped with } \\
\text { HA Formulation }\end{array}$ & Ca & P & O & Ti \\
\hline C2 & 42.37 & 22.95 & 33.51 & 1.17 \\
C5 & 34.48 & 21.06 & 41.42 & 3.04 \\
P2 & 39.15 & 23.04 & 36.57 & 1.24 \\
P5 & 30.38 & 20.52 & 48.21 & 0.89 \\
HA & 27.88 & 19.34 & 52.78 & 0 \\
TCP & 50.27 & 25.42 & 24.31 & 0 \\
\hline
\end{tabular}

sulting materials were characterized using X-ray diffraction (XRD), scanning electron microscopy (SEM), and energy dispersive spectroscopy (EDS). Moreover, osteoblast adhesion was determined in vitro in order to ascertain their cytocompatibility properties. Adhesion of anchorage-dependent cells (such as osteoblasts) is a prerequisite for subsequent cell functions, such as the deposition of calcium-containing mineral.

\section{MATERIALS AND METHODS}

\section{Sample preparation}

Pure HA, TCP, and HA doped with Ti were synthesized by well-established wet chemistry precipitation methods. ${ }^{9}$ For the synthesis of HA and TCP, $\mathrm{Ca}\left(\mathrm{NO}_{3}\right)_{2} \cdot 4 \mathrm{H}_{2} \mathrm{O}$ and $\left(\mathrm{NH}_{4}\right)_{2} \mathrm{HPO}_{4}$ were first separately dissolved in distilled water. The $\mathrm{Ca} / \mathrm{P}$ ratio should be 1.67 and 1.5 for stoichiometric $\mathrm{HA}$ and TCP, respectively. $\mathrm{NH}_{4} \mathrm{OH}$ was then added to both of these solutions to bring the $\mathrm{pH}$ to 11-12. A calcium nitrate solution was added dropwise into the continuously stirred ammonium phosphate solution. This vigorous stirring produced a milky-gelatinous solution. After stirring the HA solution at room temperature for $3 \mathrm{~h}$, it was heated to $90^{\circ} \mathrm{C}$ for $1 \mathrm{~h}$ while stirring. The solution was stirred for

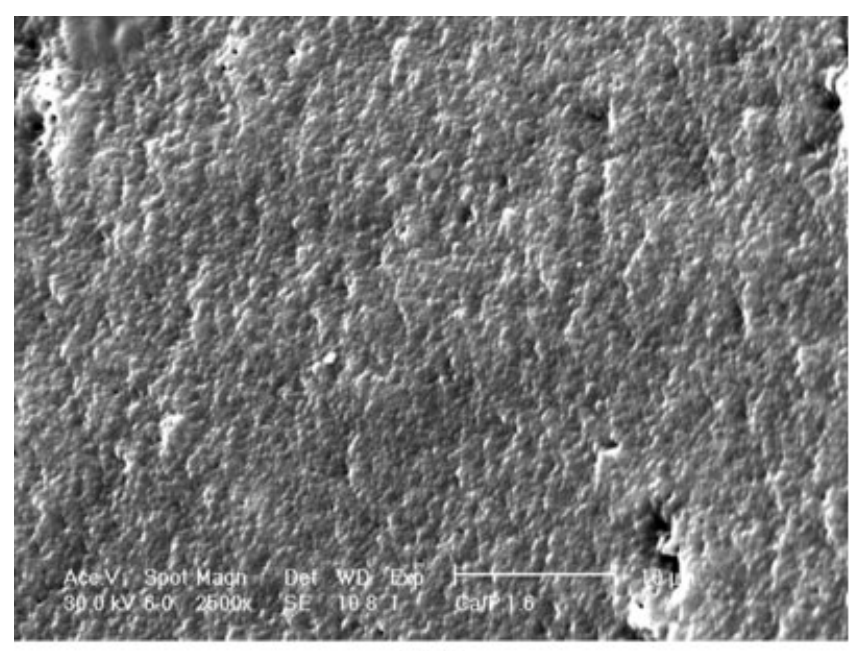

(a)

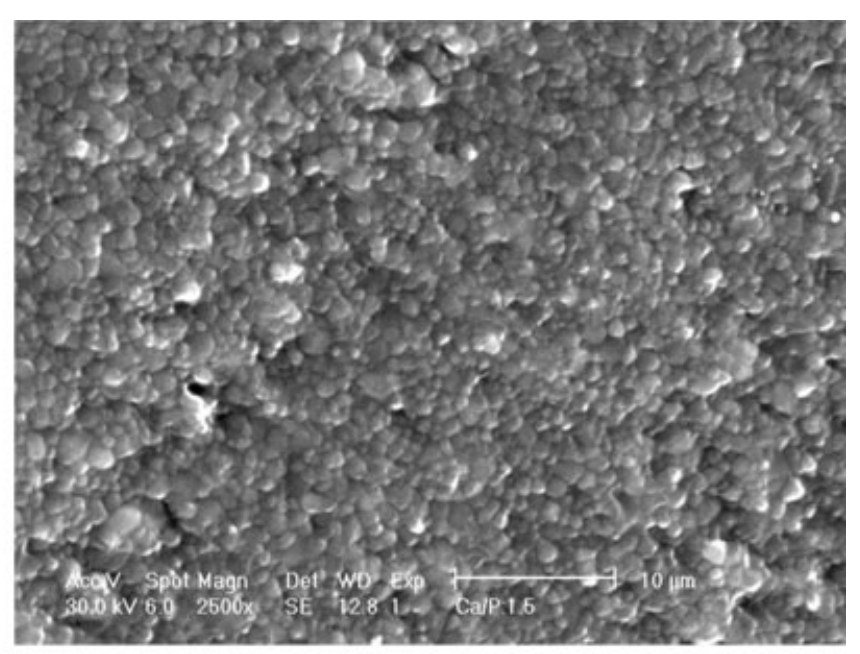

(b)

Figure 1. SEM micrographs of (a) pure HA and (b) TCP sintered at $1100^{\circ} \mathrm{C}$. Bars $=10 \mu \mathrm{m}$. 


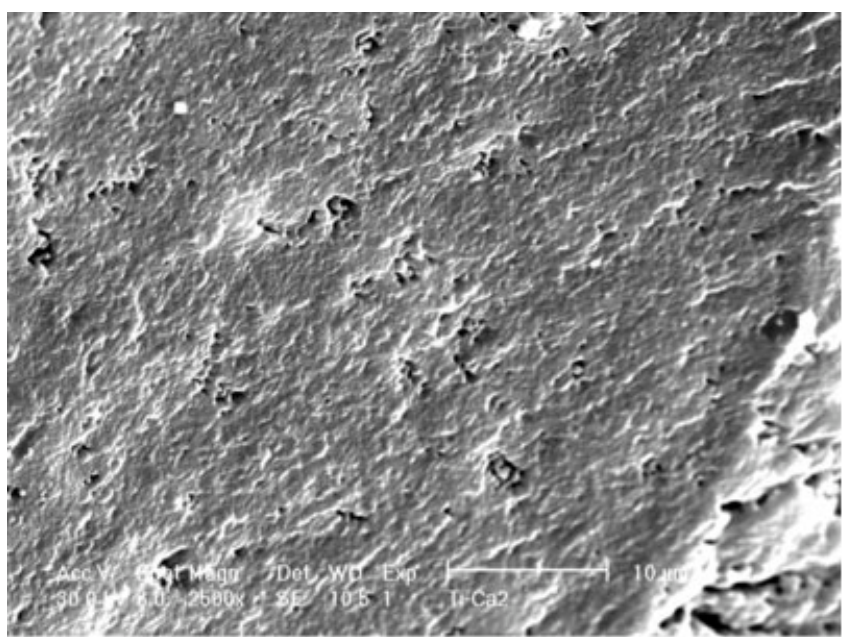

(a)

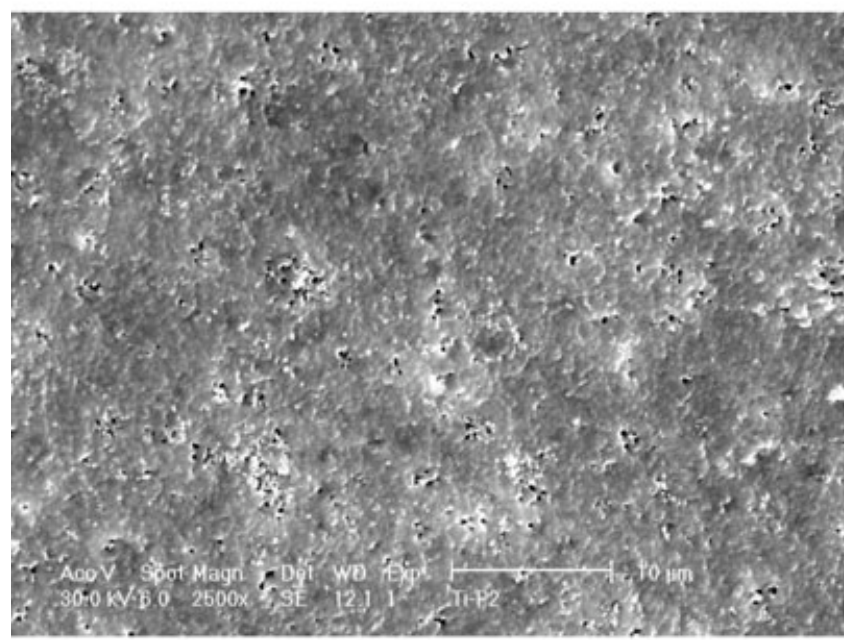

(c)

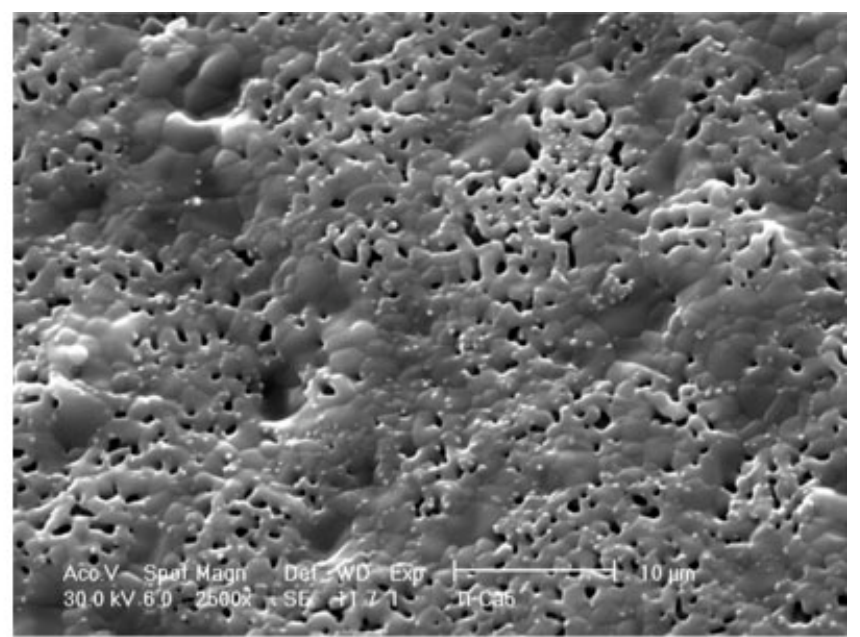

(b)

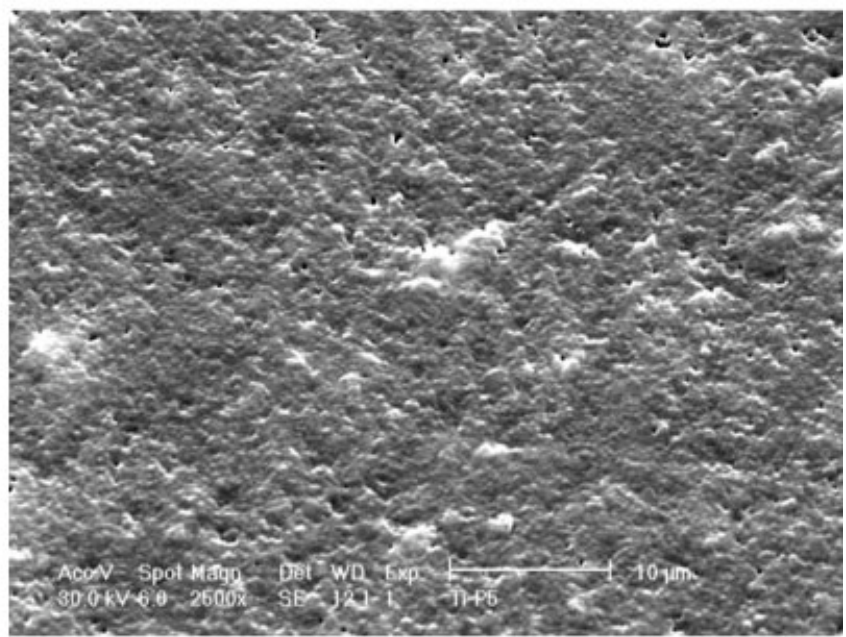

(d)

Figure 2. SEM photographs of HA doped with Ti sintered at $1100^{\circ} \mathrm{C}$ : (a) C2; (b) C5; (c) P2; and (d) P5. Bars $=10 \mu \mathrm{m}$.

one day at room temperature. The solution was then washed repeatedly to remove the unreacted ammonia and was then filtered using $0.2-\mu \mathrm{m}$ filter paper. The filtered wet cake was dried in an oven at $90^{\circ} \mathrm{C}$ overnight to remove the excess water. For Ti doped with HA, tetraethyl orthotitanate was added to the calcium nitrate solutions prepared above to obtain final concentrations of 2 and $5 \mathrm{~mol} \%$.

$\mathrm{CaTiO}_{3}$ powders were purchased from a commercial supplier (Aldrich). The synthesized powders of HA and TCP were mixed with $\mathrm{CaTiO}_{3}$ to obtain the desired weight ratios. The description and the composition of those samples are shown in Table I. For homogeneous mixing, the powders were blended with ball milling in an ethyl alcohol medium. The milled powder was then quickly filtered through a $0.2-\mu \mathrm{m}$ Millipore filter to prevent segregation due to density differences between the two types of powders. The filtered cakes were kept at $200^{\circ} \mathrm{C}$ overnight to remove the rest of the ethyl alcohol used in the washings. The cakes were then crushed and further mixed using a pestle and mortar.

The resulting powders of HA, TCP, and composites containing $\mathrm{CaTiO}_{3}$ were cold pressed into pellets at a pressure of $200 \mathrm{MPa}$ with a cylindrical cold press die. Subsequently, pellets were sintered without the application of pressure at $1100^{\circ} \mathrm{C}$ for $2 \mathrm{~h}$ in air. Finally, all the compacts were sterilized under UV light overnight before osteoblast adhesion assays.

Borosilicate glass coverslips were used as reference substrates in the cell experiments. These substrates were degreased in acetone and $70 \%$ ethanol, etched in $1 \mathrm{~N}$ $\mathrm{NaOH}$ for $1 \mathrm{~h}$, rinsed thoroughly in distilled $\mathrm{H}_{2} \mathrm{O}$, and sterilized by steam autoclaving before osteoblast adhesion assays.

\section{Material characterization}

All samples were characterized by XRD with a Philips type $\mathrm{PW} 2273 / 20$ diffractometer and $\mathrm{Cu} \mathrm{K} \alpha$ radiation at $50 \mathrm{kV} /$ $30 \mathrm{~mA}$ with a scanning speed of $1^{\circ} / \mathrm{min}$. The hexagonal lattice parameters of HA were calculated by the successive approximation technique. SEM photographs were taken with a Philips/FEI XL30FEG SEM system. Surface grain sizes of 


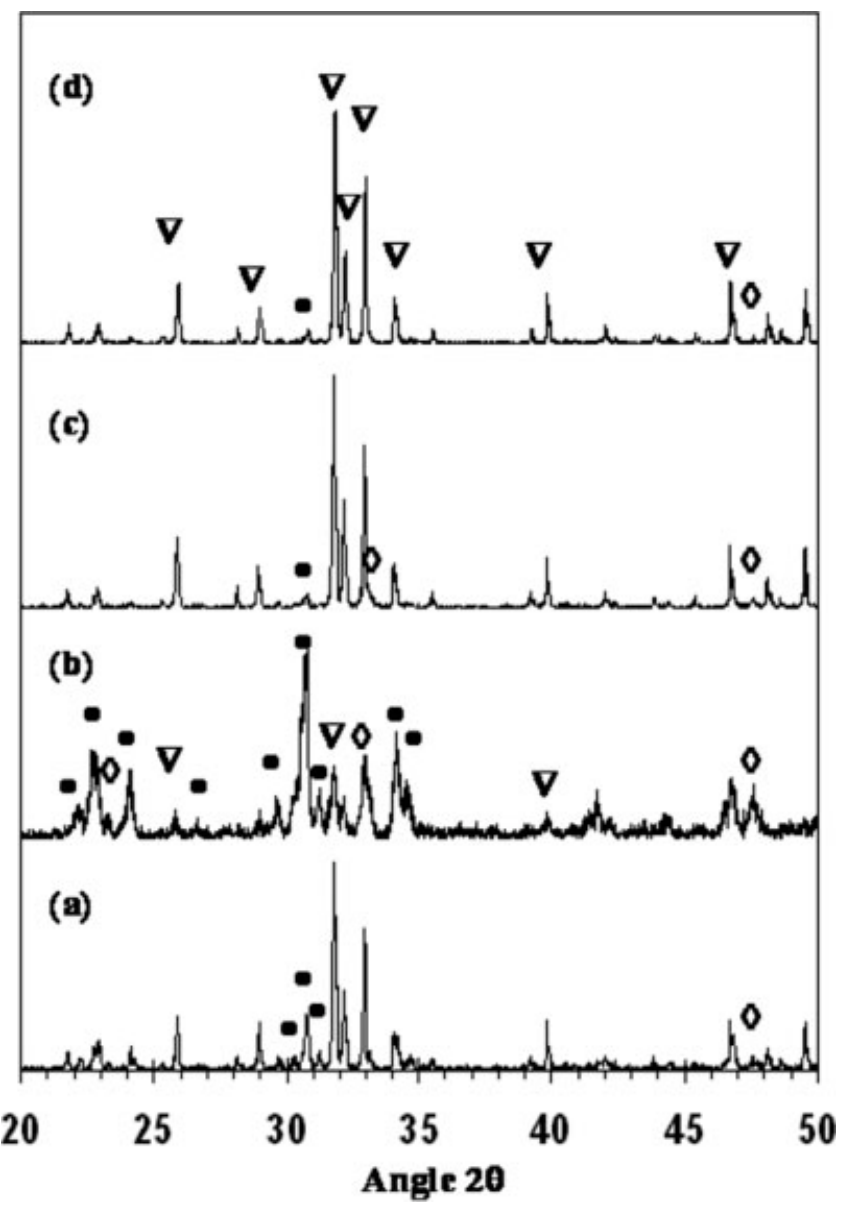

Figure 3. XRD patterns of HA doped with Ti sintered at $1100^{\circ} \mathrm{C}$ : (a) C2; (b) C5; (c) P2; and (d) P5. ( $\nabla: \mathrm{HA} ; 0$ : $\alpha-\mathrm{TCP}$ $\left.\left(\alpha-\mathrm{Ca}_{3}\left(\mathrm{PO}_{4}\right)_{6}\right) ; \diamond: \mathrm{CT}\right) . Y$-axis $=$ arbitrary units.

the compacts were determined from the SEM images by the linear intercept method. Porosity (\%) was also measured from these studies. Lastly, EDS analysis was performed using the same SEM system.

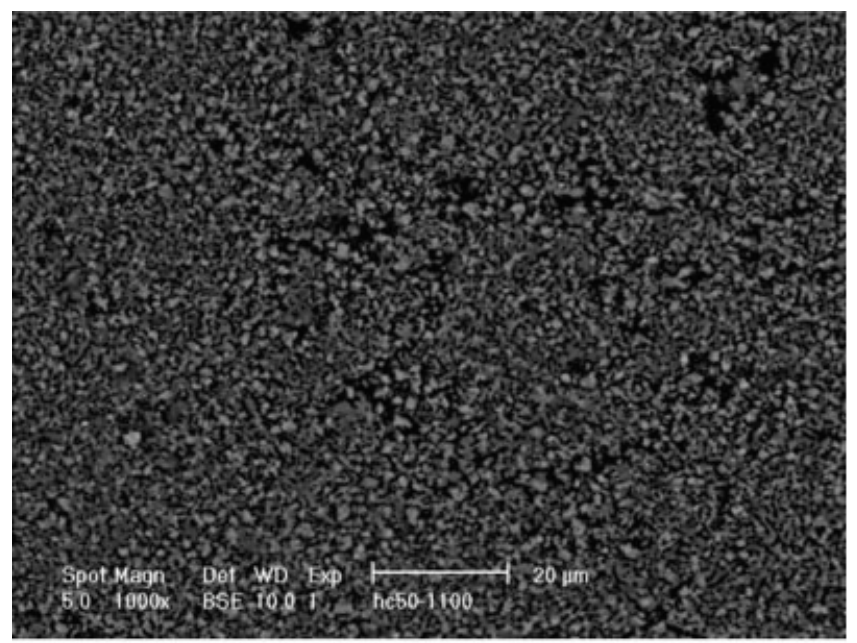

(a)

\section{Cytocompatibility tests}

Cell culture

Human osteoblasts (bone-forming cells; CRL-11372 American Type Culture Collection) were cultured in Dulbecco's modified Eagle's medium (DMEM; GIBCO, Grand Island, NY) supplemented with $10 \%$ fetal bovine serum (FBS; Hyclone) and $1 \%$ penicillin/streptomycin ( $\mathrm{P} / \mathrm{S}$; Hyclone) under standard cell culture conditions, that is, a sterile, $37^{\circ} \mathrm{C}$, humidified, $5 \% \mathrm{CO}_{2} / 95 \%$ air environment. Cells at population numbers 6-9 were used in the experiments.

\section{Osteoblast adhesion}

All sterilized substrates listed in Table I were placed in 12-well tissue culture plates (Corning, New York) and were rinsed three times with sterilized phosphate buffered saline (PBS; a solution containing $8 \mathrm{~g} \mathrm{NaCl}, 0.2 \mathrm{~g} \mathrm{KCl}, 1.5 \mathrm{~g}$ $\mathrm{Na}_{2} \mathrm{HPO}_{4}$, and $0.2 \mathrm{~g} \mathrm{KH}_{2} \mathrm{PO}_{4}$ in $1000 \mathrm{~mL}$ DI water adjusted to a $\mathrm{pH}$ of 7.4; all chemicals were from Sigma). Osteoblasts were then seeded at a concentration of 2500 cells $/ \mathrm{cm}^{2}$ onto the compacts of interest in $2 \mathrm{~mL}$ of DMEM supplemented with $10 \%$ FBS and 1\% P/S and were then incubated under standard cell culture conditions for $4 \mathrm{~h}$. After that time period, non-adherent cells were removed by rinsing with PBS and adherent cells were then fixed with formaldehyde (Fisher Scientific, Pittsburgh, PA) and stained with Hoechst 33258 dye (Sigma); the cell nuclei were, thus, visualized and counted under a fluorescence microscope (Leica, excitation wavelength $365 \mathrm{~nm}$ and emission wavelength $400 \mathrm{~nm}$ ). Cell counts were expressed as the average number of cells on eight random fields per substrate. Typical osteoblast morphologies were also digitally acquired. All experiments were run in triplicate and cell adhesion was evaluated based on the mean number of adherent cells. Numerical data were analyzed using standard analysis of variance techniques; statistical significance was considered at $p<0.05$.

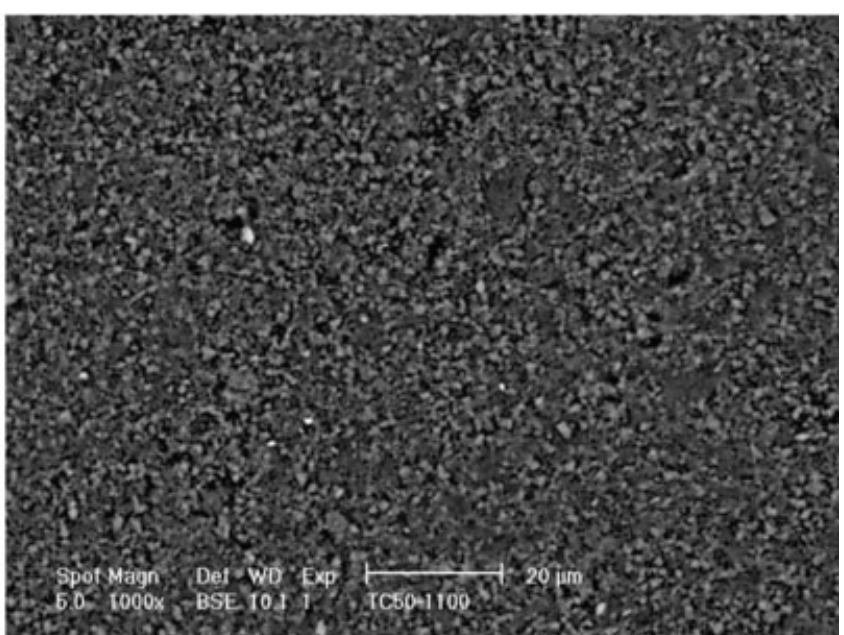

(b)

Figure 4. SEM backscattering photographs of composites sintered at $1100^{\circ} \mathrm{C}$ : (a) HC50 and (b) TC50. Bars $=20 \mu \mathrm{m}$. 


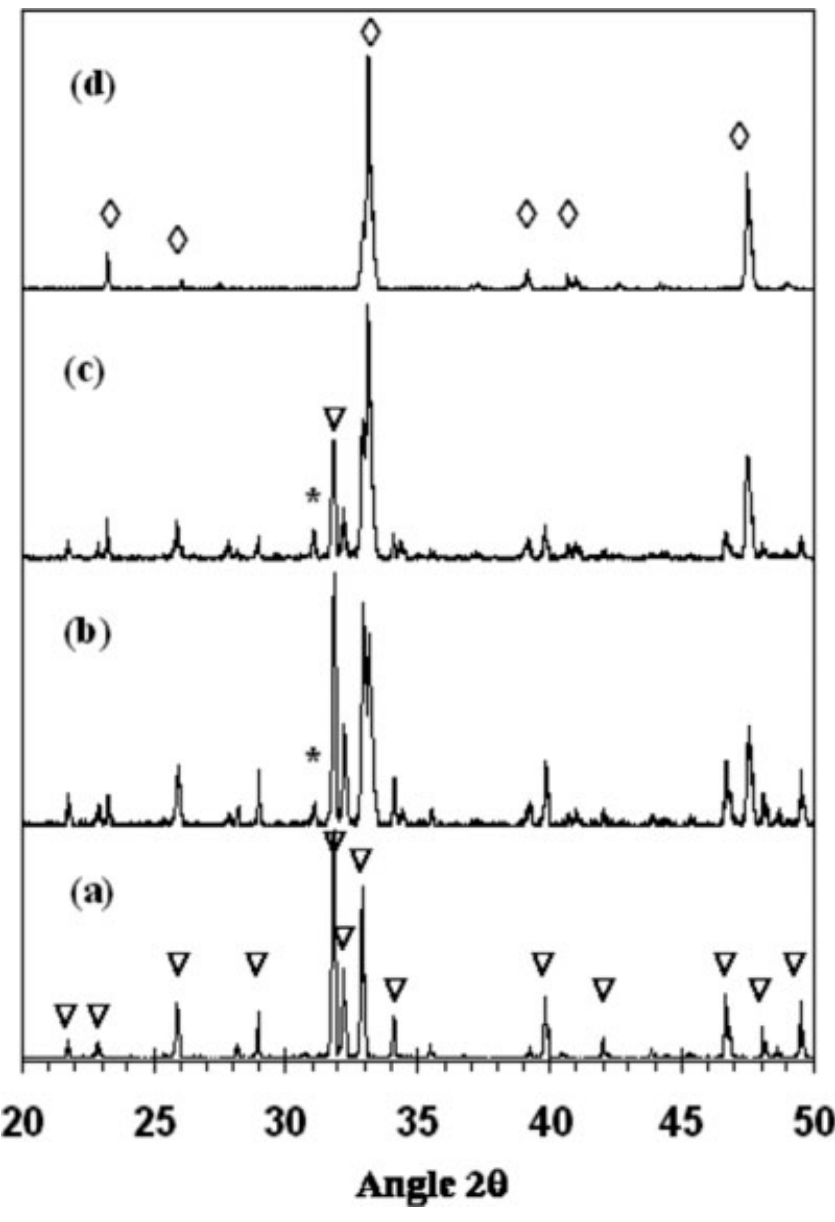

Figure 5. $\mathrm{XRD}$ patterns of composites sintered at $1100^{\circ} \mathrm{C}$ : (a) HA; (b) HC30; (c) HC50; and (d) CT. ( $\nabla$ : HA; *: $\beta$-TCP $\left.\left(\beta-\mathrm{Ca}_{3}\left(\mathrm{PO}_{4}\right)_{6}\right) ; \diamond: \mathrm{CT}\right)$. $Y$-axis $=$ arbitrary units.

\section{RESULTS}

\section{Material characterization}

Results of this study showed that both HA and TCP were almost completely densified when sintered at $1100^{\circ} \mathrm{C}$ for $2 \mathrm{~h}$ (Fig. 1). The average grain sizes of $\mathrm{HA}$ and TCP were $480 \mathrm{~nm}$ and $1.4 \mu \mathrm{m}$, respectively. The grain sizes of C2, C5, P2, and P5 were 355, 1600, 403, and $330 \mathrm{~nm}$, respectively. In contrast, the HA doped with Ti samples had significant surface porosity (Fig. 2). Specifically, C5 had the highest (52\%) amount of surface porosity followed by C2 (33\%) and P2 (18\%) with the next highest porosity. P5 (4\%) had the least amount of surface porosity among the HA doped with Ti formulations.

For C2, results of this study showed that the dominant phase was $\mathrm{HA}$; however, $\alpha-\mathrm{Ca}_{3}\left(\mathrm{PO}_{4}\right)_{6}$ and $\mathrm{CaTiO}_{3}$ phases were also detected (Fig. 3). For C5, HA was not stable as exemplified by the strong presence of $\alpha-\mathrm{Ca}_{3}\left(\mathrm{PO}_{4}\right)_{6}$ and $\mathrm{CaTiO}_{3}$ phases with some minor HA phase observed. For P2 and P5, similar to

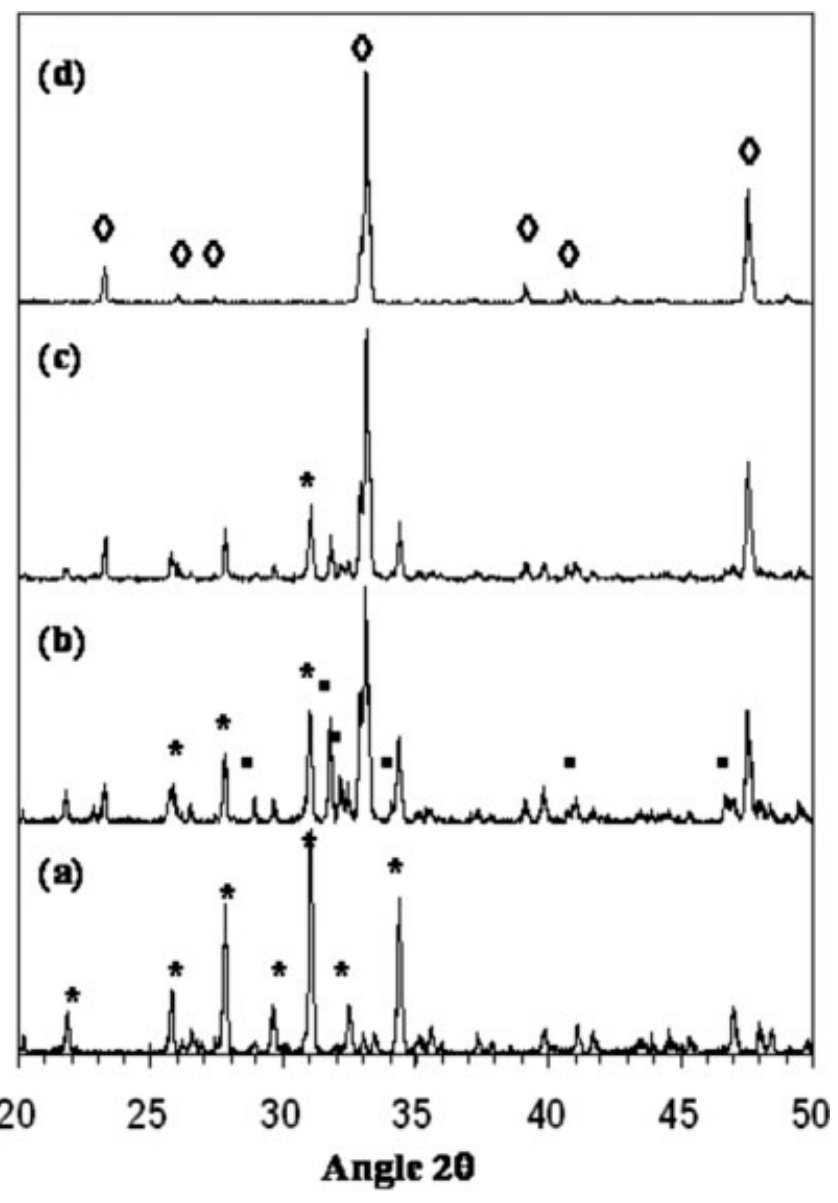

Figure 6. XRD patterns of composites sintered at $1100^{\circ} \mathrm{C}$ : (a) TCP; (b) TC30; (c) TC50; and (d) CT. (*: $\beta$-TCP ( $\beta$ $\left.\left.\mathrm{Ca}_{3}\left(\mathrm{PO}_{4}\right)_{6}\right) ; \mathbf{\square}: \mathrm{Ca}_{9} \mathrm{HPO}_{4}\left(\mathrm{PO}_{4}\right)_{5} \mathrm{OH} ; \diamond: \mathrm{CT}\right) . \quad$-axis $=$ arbitrary units.

$\mathrm{C} 2$, the major phase was HA with minor amounts of $\alpha-\mathrm{Ca}_{3}\left(\mathrm{PO}_{4}\right)_{6}$ and $\mathrm{CaTiO}_{3}$. In this manner, the results of this study demonstrated that as the Ti concentration increased in the compacts of interest, $\alpha-\mathrm{Ca}_{3}\left(\mathrm{PO}_{4}\right)_{6}$ and $\mathrm{CaTiO}_{3}$ phases became more stable. However,

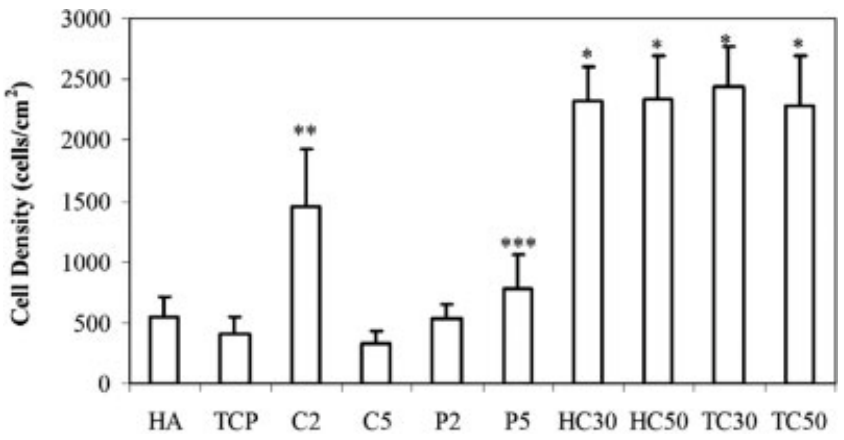

Figure 7. Increased osteoblast adhesion on nanograined $\mathrm{HA}$ and TCP $\mathrm{CaTiO}_{3}$ composites. Values are mean \pm SEM; $n=3 ;{ }^{*} p<0.05$ (compared to HA, TCP, and HA doped with Ti); ${ }^{* *} p<0.05$ (compared to P5, P2, C5, HA, and TCP); and ${ }^{* * *} p<0.05$ (compared to C5, P2, and TCP). 

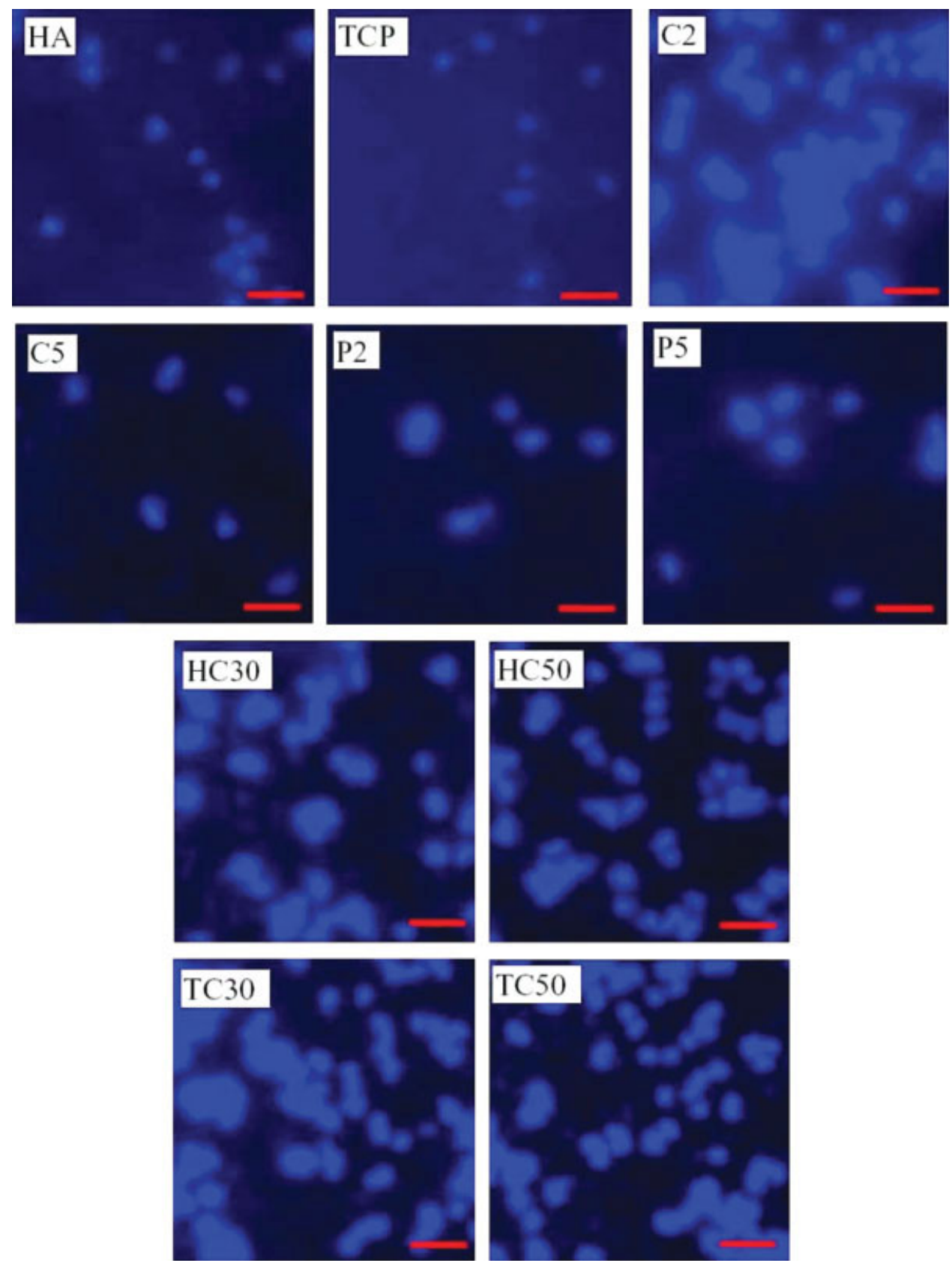

Figure 8. Fluorescence micrographs demonstrating increased osteoblast adhesion on nanograined HA and TCP containing $\mathrm{CaTiO}_{3}$. Magnification bars: $50 \mu \mathrm{m}$. [Color figure can be viewed in the online issue, which is available at www.interscience. wiley.com.]

as the concentration of these phases increased, so did porosity. The formation of pores in compacts with increased amounts of $\mathrm{Ti}$ may be due to the loss of hydroxyl groups (and associated saturated water) from $\mathrm{HA}$ leading to the formation of $\alpha$ $\mathrm{Ca}_{3}\left(\mathrm{PO}_{4}\right)_{6}$.

Results of this study also demonstrated that in C2, P2, and P5, both lattice parameters $a$ and $c$ in the hexagonal crystal structure decreased when compared to those of pure HA; this implied that the HA crystal structure decreased in volume with increased amounts of $\mathrm{Ti}$ (Table III).
For the HC50 and TC50 samples, SEM analyses showed a homogeneous mixing of the composite powders (Fig. 4). XRD patterns of $\mathrm{HA}: \mathrm{CaTiO}_{3}$ further demonstrated a small amount of $\beta-\mathrm{Ca}_{3}\left(\mathrm{PO}_{4}\right)_{6}$ detected in both HC30 and HC50 most probably due to the slight dissociation of HA (Fig. 5). However, $\mathrm{HA}$ and $\mathrm{CaTiO}_{3}$ phases remained stable in $\mathrm{HC} 30$ and HC50. On the other hand, the XRD patterns for TCP:CaTiO 3 composites showed a slight amount of $\mathrm{Ca}_{9} \mathrm{HPO}_{4}\left(\mathrm{PO}_{4}\right)_{5} \mathrm{OH}$ phase formation in addition to TCP and $\mathrm{CaTiO}_{3}$ phases (Fig. 6). Little to no porosity was observed on the HC30/50 and TC30/50 composites. 


\section{Cytocompatibility properties}

Osteoblast adhesion

Results of this study showed that osteoblast adhesion was significantly greater on the $\mathrm{HA}: \mathrm{CaTiO}_{3}$ composites and TCP:CaTiO ${ }_{3}$ composites than on pure HA, pure TCP, and HA doped with Ti (Fig. 7). In fact, osteoblast adhesion on HA and TCP composites with $\mathrm{CaTiO}_{3}$ was almost 4.5 times higher than that on pure HA. However, no significant differences in osteoblast adhesion among the $\mathrm{HA}: \mathrm{CaTiO}_{3}$ composites and among the TCP:CaTiO ${ }_{3}$ composites were detected. Moreover, among the HA doped with Ti compacts, osteoblast adhesion was significantly greater on C2 than on P5, P2, C5, HA, and TCP. Osteoblast adhesion was also significantly greater on P5 than on C5, P2, and TCP. Osteoblast adhesion was not significantly different between HA and TCP. Although all $\mathrm{CaTiO}_{3}$ composites showed excellent osteoblast adhesion results, $\mathrm{Ca}_{9} \mathrm{HPO}_{4}\left(\mathrm{PO}_{4}\right)_{5} \mathrm{OH}$ phase formation in TCP:CaTiO${ }_{3}$ increased osteoblast adhesion the most.

\section{Osteoblast morphology}

Visual inspection of osteoblast morphology on the compacts supported quantitative osteoblast adhesion results. Specifically, osteoblasts were more spread on $\mathrm{HA}: \mathrm{CaTiO}_{3}$ composites and TCP:CaTiO${ }_{3}$ composites than on the pure HA and TCP (Fig. 8). Osteoblasts were also more spread on $\mathrm{C} 2$ than on $\mathrm{C} 5, \mathrm{P} 2$, and $\mathrm{P} 5$.

\section{DISCUSSION}

In all doped apatites, the HA crystal structure shrank in volume; both lattice parameters $a$ and $c$ in the HA hexagonal structure were smaller than in pure HA. Since the ionic radius of Ti is smaller than $\mathrm{Ca}, \mathrm{O}$, and $\mathrm{P}$ in $\mathrm{HA}$, it is plausible that the substitution of Ti resulted in a shrinkage of the apatite crystal. This finding is in an agreement with a previous study by Ribeiroa et al. ${ }^{4}$ who also reported decreased lattice parameters $a$ and $c$ with increasing Ti concentrations in HA. Specifically, for the present study, this suggested that more Ti ions were added to the HA crystal lattice structure for C2 that for P5; again, C2 and P5 were the Ti doped with HA according to the weight percentages shown in Table II. Since the HA phase was not stable for $\mathrm{C} 5$, these lattice parameter calculations were not applied; $\mathrm{C} 5$ was also Ti doped with HA according to the weight percentages in Table II.

More importantly, results of this in vitro study provided evidence of increased osteoblast adhesion on HA doped with Ti as well as HA and TCP composites doped with $\mathrm{CaTiO}_{3}$. Such information is useful when collectively considering the improved cytocompatibility properties of HA for orthopedic applications, since it also means that $\mathrm{Ti}$ incorporation into the HA structure (to a certain extent) does not decrease osteoblast adhesion capacity until the HA structure is dissociated into a $\alpha$-TCP phase as observed for C5. It is intriguing to ponder why. Clearly, there are chemistry changes in the composites due to the addition of Ti to the HA lattice structure that may have influenced initial protein interactions important for mediating osteoblast adhesion. The solubility limit of Ti in HA was not specifically examined in this study; however, it has been previously reported to be $200 \mathrm{ppm}$. $^{4}$ Thus, increasing $\mathrm{Ti}$ in HA may cause the formation of $\mathrm{CaTiO}_{3}$ and $\alpha-$ TCP. For Ti addition beyond this limit, HA becomes completely unstable. In this case, $\alpha$-TCP and $\mathrm{CaTiO}_{3}$ were the only stable phases; importantly, osteoblast adhesion considerably decreased when HA instability occurred. In this light, the present study confirmed other studies which have demonstrated increased osteoblast adhesion on HA compared to $\alpha$-TCP..$^{10}$

Additional material properties that may have influenced osteoblast adhesion on the Ti-doped HA are grain size and roughness created by changes in porosity. ${ }^{10}$ SEM analysis revealed that for each of the HA doped with Ti composites (except for C5), nanometer grain sizes were measured (Table III). In this manner, increased osteoblast adhesion on compacts with similar chemistry but smaller grain sizes confirms other reports in the literature which have shown greater osteoblast adhesion, proliferation, alkaline phospha-

TABLE III

Lattice Parameter, Grain Size, and Porosity of Pure HA and HA Doped with Ti

\begin{tabular}{|c|c|c|c|c|c|c|c|c|}
\hline \multirow[b]{2}{*}{ Sample } & \multicolumn{4}{|c|}{$\begin{array}{l}\text { Hexagonal Lattice Parameters } \\
a \text { and } c \text { and } \Delta a \text { and } \Delta c\end{array}$} & \multicolumn{2}{|c|}{$\begin{array}{c}\text { Unit Cell Volumes } V \text { and } \\
\text { Differences } \Delta V\end{array}$} & \multirow{2}{*}{$\begin{array}{l}\text { Grain Size } \\
\quad D(\mathrm{~nm})\end{array}$} & \multirow{2}{*}{$\begin{array}{c}\% \text { Porosity } \\
P\end{array}$} \\
\hline & $a$ & $\Delta a$ & $c$ & $\Delta c$ & $V$ & $\Delta V$ & & \\
\hline $\mathrm{HA}$ & 9.427 & 0 & 6.888 & 0 & 530.1 & 0 & 225 & 0 \\
\hline $\mathrm{C} 2$ & 9.420 & -0.007 & 6.861 & -0.027 & 527.2 & -2.9 & 355 & 33 \\
\hline C5 & \multicolumn{6}{|c|}{ Not determined ${ }^{a}$} & 1600 & 52 \\
\hline P2 & 9.425 & -0.002 & 6.882 & -0.006 & 529.4 & -0.7 & 255 & 18 \\
\hline P5 & 9.422 & -0.005 & 6.873 & -0.015 & 528.4 & -1.7 & 280 & 4 \\
\hline
\end{tabular}

${ }^{\mathrm{a}}$ The lattice parameters of C5 were not determined because of the high amount of HA decomposition from XRD data. 
tase synthesis, and calcium deposition on pure HA with 67 compared to $167 \mathrm{~nm}$ grain sizes. ${ }^{11}$ Recent studies have furthered this in vitro data and have demonstrated increased infiltration of rat calvaria bone into tantalum scaffolds coated with nanometer compared to conventional HA as early as 2 weeks. ${ }^{12}$ Such promoted osteoblast functions on smaller nanometer grain size HA was attributed to their unique surface properties (due to increased numbers of grain boundaries, surface defects, etc.) that increased the adsorption of proteins known to promote osteoblast adhesion (such as vitronectin). ${ }^{13}$ The same events may be happening here.

Nonetheless, it is important to keep in mind that although osteoblast adhesion is a necessary step for osteoblast long-term functions (such as calcium deposition), more studies are clearly needed to determine subsequent functions of osteoblasts on the substrates of interest to the present study. More studies are also needed to determine an exact mechanism as to why the trends observed in this study are occurring, such as by examining altered initial protein interactions on either HA or TCP with $\mathrm{CaTiO}_{3}$ important for osteoblast adhesion.

\section{CONCLUSIONS}

In summary, this study provided important results on the cytocompatibility properties of Ti doped with $\mathrm{HA}$ in the form of ionic substitutions and $\mathrm{CaTiO}_{3}$ additions. Results showed that osteoblast adhesion increased with greater Ti substitution in the HA lattice. In addition, osteoblast adhesion on either HA or TCP composites with $\mathrm{CaTiO}_{3}$ was almost 4.5 times better than over pure HA. Material characterization studies revealed that enhanced osteoblast adhesion on these compacts may be due to increasing shrinkage in the unit lattice parameters and decreasing nanometer grain size which may be associated with increasing amounts of Ti substitution in the HA lattice. Although all $\mathrm{CaTiO}_{3}$ composites showed excel- lent osteoblast adhesion results, $\mathrm{Ca}_{9} \mathrm{HPO}_{4}\left(\mathrm{PO}_{4}\right)_{5} \mathrm{OH}$ phase formation into TCP:CaTiO 3 increased osteoblast adhesion the most; because of these reasons, these materials should be further studied for orthopedic applications.

\section{References}

1. Ergun C, Doremus RH, Lanford WB. Interface reaction/diffusion in hydroxylapatite-coated SS316L and CoCrMo alloys. Acta Materialia 2004;52:4767-4772.

2. Webster TJ, Ergun C, Doremus RH, Lanford WB. Increased osteoblast adhesion on titanium-coated hydroxylapatite that forms $\mathrm{CaTiO}_{3}$. J Biomed Mater Res A 2003;67:975-980.

3. Ergun C, Doremus RH, Lanford WB. Hydroxylapatite and titanium: Interfacial reactions. J Biomed Mater Res A 2003;65: 336-343.

4. Ribeiroa CC, Gibsond I, Barbosaa MA. The uptake of titanium ions by hydroxyapatite particles-structural changes and possible mechanisms. Biomaterials 2006;27:1749-1761.

5. Ergun C, Doremus RH. Thermal stability of hydroxylapatitetitanium and hydroxylapatite-titania composites. Turk J Eng Environ Sci 2003;27:423-429.

6. Asami K, Saito K, Ohtsu N, Nagata S, Hanawa T. Titaniumimplanted $\mathrm{CaTiO}_{3}$ films and their changes in Hanks' solution. Surf Interface Anal 2003;35:483-488.

7. Manso M, Langlet M, Martinez-Duart JM. Testing sol-gel $\mathrm{CaTiO}_{3}$ coatings for biocompatible applications. Mater Sci Eng C Biomimetic Supramol Syst 2003;23:447-450.

8. Holliday S, Stanishevsky A. Crystallization of $\mathrm{CaTiO}_{3}$ by solgel synthesis and rapid thermal processing. Surf Coat Technol 2004;188:741-744.

9. Ergun C, Webster TJ, Bizios R, Doremus RH. Hydroxylapatite with substituted $\mathrm{Mg}, \mathrm{Zn}, \mathrm{Cd}$, and Y: Structure and microstructure. J Biomed Mater Res 2002;59:305-311.

10. Sato M, Slamovich EB, Webster TJ. Enhanced osteoblast adhesion on hydrothermally treated hydroxyapatite/titania/poly (lactide-co-glycolide) sol-gel titanium coatings. Biomaterials 2005;26:1349-1357.

11. Webster TJ, Ergun C, Doremus RH, Siegel RW, Bizios R. Enhanced osteoblast adhesion on nanophase ceramics. Biomaterials 2000;21:1803-1810.

12. Sato M, An HY, Webster TJ. Increased in vivo infiltration of bone into tantalum scaffolds coated with nanophase compared to conventional hydroxyapatite. Int J Nanomed. Forthcoming.

13. Webster TJ, Ergun C, Doremus RH, Siegel RW, Bizios R. Specific protein interactions mediate enhanced osteoblast functions on nanophase ceramics. Biomaterials 2001;22:1327-1333. 